\title{
EL RENACIMIENTO: UN CONTEXTO PARA EL SURGIMIENTO DEL CONCEPTO PEDAGÓGICO 'FORMACIÓN'
}

\author{
María Eugenia Venegas Renauld
}

\author{
Recibido 8-XI-2003 • Aceptado 18-XII-2003
}

\begin{abstract}
Resumen: El pensamiento griego y la cosmovisión cristiana, han sido troqueladores de la cultura pedagógica de Occidente. En un rastreo histórico a la aparición del concepto "formación", como término pedagógico, el Renacimiento constituye un período que proporciona evidencias para situarlo. En este artículo, se realiza una discusión al respecto analizando el aporte de algunos humanistas y las condiciones contextuales y léxicas que permiten plantear la hipótesis de su construcción como tal en ese momento y desde la perspectiva de la noción que está presente en García Carrasco y García del Dujo.
\end{abstract}

Palabras clave: Génesis Pedagógica de la 'Formación', Contexto Histórico Concepto 'Formación', 'Formación' en el Renacimiento, Concepto Pedagógico de ‘Formación', Aparición Concepto ‘Formación’.

\section{La formación como concepto pedagógico}

\section{La formación en el Renacimiento}

El Renacimiento puede ser caracterizado de manera preliminar atendiendo a las siguientes condiciones: el recelo que primó en la sociedad, principalmente, en los grupos letrados respecto a la cultura medieval; la síntesis de la cultura clásica; los procesos de innovación y renovación cultural y económica y, los procesos de continuidad de la cultura medieval, en un claro ascenso y transformación, pero no de ruptura total, mediante los que se asimilaron los valores culturales de la Edad Media, en marcos contextuales diferentes. Aquello que en apariencia podría verse como antagonismo y ruptura cultural, no fue más que la continuidad -no linealidad-propia de las épocas que se caracterizan por ser tensas, de nexos y de dinamismo (Capitán, 1984).

La realidad educativa en el Renacimiento, no puede verse de manera fragmentada. Diversas ideas y prácticas propias de la Edad Media, siguieron vigentes en el campo educativo y se modificaron lentamente, conforme al desarrollo y evolución de los procesos de transformación social, política, económica y cultural. Por ello es que la cultura conformada en el Renacimiento, hay que entenderla en 
términos de los resultados de diversos fenómenos en esos órdenes a lo largo de los siglos XV y XVI.

En un análisis sociológico de la educación occidental contemporánea, plantea Lerena (1983) que en la Ilustración, la educación y la estructura social estuvieron cimentadas en la ideología promovida por el cristianismo y la cultura griega. En este trabajo se asume que, en los siglos anteriores al Renacimiento, están contenidos muchos de los gérmenes de la educación de este período, por lo que, tanto en la ideología como en las prácticas educativas, vertidas y recogidas en las obras literarias que dan cuenta de esa época, se pueden encontrar evidencias del empleo del concepto de formación, así como pistas para comprender, cómo se fue construyendo en tanto concepto pedagógico. Lengua, costumbres, movimientos sociales y económicos, situaciones políticas, artísticas y culturales en general, son propicias para entender la construcción del término.

Un primer elemento que contribuye a la aproximación semántica desde el contexto de esta época, es de tipo económico. Este factor fue determinante de la vida en todos los ámbitos. El nacimiento del mercado en el siglo XV, ha sido un hecho histórico fundante de la estructura de la sociedad burguesa. Las formas de vida que se generaron por el desarrollo de nuevas formas de producción económica, no se limitaron al ámbito de la economía. Estas trascendieron a todos los órdenes y sectores de la realidad: producción y evolución de la vida material, formas y productos del pensamiento, demandas y desarrollo de condiciones laborales, aspiraciones educativas y culturales de diversos grupos sociales, modos de producción, convivencia, estructuras de poder político, formas de participación social, lecturas de la realidad, formas discursivas, formas de comunicación, actitudes, religión, arte, en fin, toda la vida en sus intrincados laberintos y complejidades, tuvo en el Renacimiento los asideros para la vida moderna.
La clase burguesa, por su parte, que jugó un papel central en el ordenamiento socio-político y socio-cultural de los siglos posteriores, tiene importancia en esta aproximación, principalmente, por las demandas educativas que generó, en alto grado por las necesidades de conocimiento y de preparación para afrontar nuevas formas de relación comercial y productiva. Es viable pensar que estas nuevas demandas de educación, que trascendieron la preparación de clérigos y monjes en monasterios, abrieran oportunidades, formas de trabajo y ofertas que no se habían tenido en otros momentos. En este caso, interesa hilar un poco más fino, en el sentido de apreciar, que esos nuevos elementos que salían a la sociedad, se trasvasaron a la lengua, enriqueciéndose de manera insospechada: la necesidad de incorporar palabras nuevas, para representaciones nuevas.

Desde el campo educativo, se recupera en este trabajo, el nacimiento y desarrollo del humanismo renacentista. Entendido como el pensamiento que surgió de la circunstancia histórica en la que se reunió, el pensamiento helénico y romano, la tradición griega y el cristianismo, posibilitó, la configuración de un ideal humanista de la paideia. Se trató de la nueva paideia enraizada en la teología, cuyo mejor exponente fue Erasmo de Rotterdam $^{1}$. Incluso se ha llegado a afirmar, que fue en España donde tuvo más éxito que en cualquier otro país europeo (Delgado, 1993).

Para entender la educación que emana del humanismo renacentista, hay que entender que, a diferencia de la Edad Media, los ideales de la época se insertaron en una matriz socio-política, y estuvieron cubiertos de las ideas en torno a propuestas ciudadanas, modos de convivencia comunal y contenidos sociales, que se ensayaron en los escritos producidos. En ese sentido, toda la educación humanista no dejó de ser civilidad en todas sus expresiones, desde las formas de vida, modos de comportamiento, indicaciones políticas y aspiraciones 
humanas. La educación humanista fue politeia ${ }^{2}$ debido a su carácter socio-político, y encontró en la estructura de la clase burguesa, la circunstancia favorable para su desarrollo. Este es un factor que contribuyó a sumarse en el surgimiento de una ideología educativa que se vertió en la lengua, porque el concepto de formación, como concepto pedagógico, se vio afectado en su génesis, por esas formas de pensamiento propias de la época en la cual se emplea y específicamente, por el pensamiento de quienes lo emplearon.

La pedagogía humanista del Renacimiento, tuvo en Erasmo de Rotterdam, al ideólogo que posibilita desde su obra, acercarnos al referente conceptual del concepto 'formación'. Él expresa un ideario en el que antropológicamente el ser humano es el centro: el hombre que se hace hombre, en el desarrollo de su naturaleza espiritual y, para lo cual, necesita el conocimiento de las palabras y las cosas. Por ello, una de sus preocupaciones más intensas, fue la de que las personas hablaran y escribieran bien y de alguna manera, su perspectiva, fue de un mayor formalismo literario.

En su ideario de educación, Erasmo concibe dos postulados fundamentales: la noción de educabilidad y la vocación. La educabilidad entendida como una condición de la persona de docilidad y propensión, está enraizada en la condición humana, por cuanto la naturaleza humana es susceptible de un ordenamiento racional y es un elemento de operatividad y, la vocación, que es producto de un conjunto de rasgos individuales. Ambos conceptos, proporcionan la base para plantear, que en los fundamentos de su modelo educativo, se advierte ese mecanismo primario de modificación comportamental que García Carrasco y García del Dujo (1996, pág. 54) denominan educabilidad: “...estado innato de desespecialización y flexibilidad configurativa del comportamiento (educabilidad)..." y que representa uno de los pilares sobre los que se asienta la formación humana como concepto educativo, íntimamente vinculado a la educatividad en tanto condición efectiva de influencia sobre el ser humano. En Erasmo de Rotterdam hay un claro reconocimiento a la particular condición que poseen las personas, porque se reconoce en esa naturaleza humana susceptible de ser educada, unas condiciones que hacen que cada persona sea diferente. Es decir, que no sólo el ser humano posee la innata posibilidad y condición de ser educado, sino que esa educación operaría -racionalmente- diferente, en atención a su singularidad. Singularidad que se expresa en ese conjunto de rasgos individuales que se vierten luego en una vocación. Es importante esta fundamentación, porque aquí Erasmo deja instalada la vía por medio de la cual, correrá el concepto de formación como concepto pedagógico.

Si se parte de la idea de formación:

“(...) la consecuencia de la educabilidad del hombre, de la flexibilidad configurativa del sistema comportamental humano. (...) el correlato de las acciones humanas (de todos los órdenes de las acciones humanas), es una dimensión de la actividad humana, la cual contiene la vertiente de producción (acontecimientos, artefactos y artificios, teorías...) y la vertiente de formación (competencias, disposiciones, identificaciones, actitudes...)". (García Carrasco y García del Dujo, op. cit. pág. 60).

estamos ante la circunstancia histórica, en el pensamiento de Erasmo de Rotterdam, de una noción de formación que subyace en sus planteamientos educativos humanistas, y que se constatan en las obras Educación del Príncipe Cristiano ${ }^{3}$, el Enchiridión o Manual del Caballero Cristiano y De cómo los niños han de ser precozmente iniciados en la piedad y en las buenas letras (De Rótterdam (1964), en Capitán, op.cit.). Pero también, recuperamos de Erasmo, desde ese telos en el cual el fin del ser humano es la felicidad y el fin de la educación es la persona, los elementos que propone como intervinientes en la educación: la naturaleza, que es susceptible de ser moldeada por la educación; los preceptos, que fueron máximas para ejercer el buen gobierno; el ejemplo, que debe ser tomado de los 
evangelios y la práctica, representada en la participación política:

"Toda la sustancia de la felicidad humana se apoya principalmente en tres cosas: naturaleza, razón y ejercicio. Doy el nombre de naturaleza a la docilidad y propensión, profundamente arraigadas por las buenas acciones. Llamo razón a la doctrina constituida por avisos y preceptos. Y denomino ejercicio al uso de aquel hábito de que la Naturaleza proveyó y al que la razón dio crecimiento. La naturaleza ha menester de la razón, y el ejercicio, si la razón no lo gobierna, anda expuesto a muchos peligros y errores". (De Rotterdam, 1964. En Capitán, op. cit., pág. 293).

Este insigne renacentista planteó que la educación y la crianza, son los recursos que hacen de todo individuo, la condición para que no degenere su natural condición: "que nazca de buena índole se debe al cielo; pero que el príncipe biennacido no degenere, o que el que nació no muy a derechas quede mejorado por la educación y crianza que se le dé, es cosa que en gran parte depende de nosotros" (De Rotterdam, 1964. En Capitán, op. cit., pág. 289 ), con lo cual, nos proporciona un marco de referentes pedagógicos para comprender el ideario educativo de una época pródiga en pensamiento.

En Erasmo, existe entonces, esa condición de educabilidad que se inscribe en la naturaleza humana, y que es fundante de la formación tal y como nos lo anticiparan García Carrasco y García del Dujo. Aunque todavía no asoma la palabra formación en el sentido explícito, podemos acercarnos a un panorama educativo, que da cabida desde el léxico que lo constituye, al concepto de formación. Enseñanza, adoctrinamiento, instrucción, inculcación, representan voces de una semántica educativa, que no se encuentra en Erasmo, sino en el discurso de otros renacentistas como Tomás Moro a través de su utopía de una sociedad presidida por la razón y normas particulares de vida sustentadas en el Evangelio Cristiano; en Campanella y su perspectiva positiva y religioso-naturalista y, en Maquiavelo, a través de la idea del poder para la praxis política.
El Renacimiento plantea una educación que se asume incardinada en el individuo en tanto sujeto perteneciente a una comunidad que está además estructurada en una jerarquía de clases sociales. Es una idea de la educación entronizada como cultura $^{4}$, con un claro reconocimiento a los aportes que podrían derivarse de otras culturas $^{5}$, en especial, de la cristiana. Y en esa perspectiva de educación, la 'formación' germina en un lento proceso de diferenciación, en la medida en que la educación se afianza en la institucionalización y se construye como recurso político mediante el poder de las clases cultural y políticamente dominantes.

\section{El Renacimiento pedagógico en España}

El Renacimiento en España, y concretamente en el campo pedagógico, se expresa en una serie de reflexiones en torno a la moral, la educación y el desarrollo humano, proporcionando un perfil de persona, así como los medios para conseguirlo. Todo el pensamiento que se configuró en esa época, fue de un lento pero continuo desarrollo que se diferenció de manera importante del Renacimiento vertiginoso de otras latitudes europeas. Esto se debió a la circunstancia histórica de la España Imperial, contenida en cinco factores principales (Capitán, op. cit.):

a. Una tendencia más armoniosa entre la tradición clásica y la medieval, de modo que el período en España, fue más continuidad con la época anterior y síntesis de ambas tradiciones. Puede verse esto en el empleo de la lengua latina y el uso del castellano, aspecto que luego tomaría una ruta hacia el predominio del castellano.

b. El interés socio-político y el desarrollo económico en el nivel nacional, en el que la incipiente burguesía 
constituyó un factor de gran peso en la nueva configuración social y en la distribución del poder.

c. La cultura como elemento de moderación en las relaciones con respecto a las jerarquías política y religiosa. Un paulatino proceso de expansión del conocimiento, por ejemplo, desde las clases aristocráticas hacia el pueblo, que representó en líneas generales, una mayor distribución cultural. No obstante y de manera paradójica, posibilitó la conformación de una sólida jerarquización social y económica.

d. La formación humana integral tomando como marco los estudios de Humanidades. Tanto la retórica, como la producción literaria en general, significaron el modus operandi para el logro de una formación integral de las facultades humanas: el logos en la palabra y el pensamiento, el ethos como conducta y moral y, la politeia, como la participación en la vida social.

e. El acercamiento de la verdad moral a la responsabilidad personal, es decir, el hombre mismo apela a su responsabilidad.

A partir de estas características de la época renacentista, se puede acotar que, en el caso español, el Renacimiento estuvo, en el campo pedagógico, fundamentado, manifiesto y apoyado, en una literatura didáctico-moral, que no es ni más ni menos que una nueva forma del ideal ascéticoreligioso del siglo anterior, el cual lleva en sí mismo, algunos anticipos renacentistas. Tal caso se encuentra en la obra de Anfonso de Cartagena ${ }^{6}$ y su ideario de formación física, científica intelectual y cristiana con la base otorgada por la tradición clásica; en Iñigo López de Mendoza, el Marqués de Santillana y sus intenciones morales ${ }^{7}$; y en Alonso de Palencia, fundamental por su aporte al conocimiento del vocabulario y gramática de la época ${ }^{8}$.

Propiamente de este período, un caso realmente importante para la cultura, es la producción literaria de Elio Antonio Nebrija. Para esta aproximación semántica al concepto pedagógico formación, la obra De liberis educandis, escrita en el año 1509 y el Vocabulario Latino-español, escrito en 1492 en Salamanca, constituyen dos valiosos referentes en el tema que nos ocupa. Para Nebrija, la lengua es progreso de cultura y un factor estructurante de la realidad. En ella, está contenida la historia de las sociedades. Por eso su obra es una fuente de incalculable valor.

De liberis educandis libellus o De la educación de los hijos ${ }^{9}$ que constituye un escrito de pedagogía, facilita una aproximación al campo de significaciones pedagógicas a partir del lenguaje empleado. En esta producción se encuentra lo siguiente: "nadie mejor que tú, padre, puede dar precepto a tus hijos" (en Capitán, op. cit., págs. 356-257) "Nemo melius quam tu liberis tuis praecepta dare potest, ... (De Nebrija, 1981, pág. 74). ¿Refiere a 'dar formación'? Incluso desde los títulos de los capítulos que estructuran la obra, conceptos como: cuidado, instrucción, educación, educado, educarse, enseñar, preceptor, nutrido, todos ellos relativos al campo de la educación, están presentes, no así, el término exacto de formación. Hay importantes referencias al universo semántico del término (los términos subrayados se destacan para este trabajo) en latín, tal y como se puede apreciar seguidamente:

\section{Formar, formación}

Aiebas namque inanes esse parentum cogitationes si in eo laborent, ut amplissima rei familiaris posteritati suae fundamenta aiciant, quibus vero ea comparantur filiis quales futuri sint non current. Quades si quid habes Antoni in quod possis huic sollicitudini neae opem ferre, id quod te ex multa lectione non dubito assecutum, ne graveris amico roganti communicare. 
"Afirmabas que serían vanos los esfuerzos de los padres, si trabajando por dar unos sólidos fundamentos a su familia, y a su patrimonio de cara al futuro, no cuidasen de formar a sus hijos para el día de mañana. Por lo que, si puedes Antonio, ayúdame -dijisteen este cuidado; cosa que no dudo conseguirás con tu formación. (De Nebrija, op. cit., págs.72-73).

Quae sit cura adhibenda puerorum corporibus formandis.

"Del cuidado de la formación del cuerpo de los niños." (De Nebrija, 1981, págs. 104-105).

Quo tempore pueris incipiendum est dare operan litteris et moribus.

"A qué edad los niños deben comenzar la instrucción y formación de costumbres” (De Nebrija, 1981, págs. 116-117).

Cum igitur institutum opus eo tendant ut ex pueris bonos sapientesque virtos efficere possimus, sic litterarum ratio habenda est, ut mores non negligantur. "No es lícito mezclar estas cosas. Como quiera que la obra educativa tienda a hacer de los niños hombres sabios y buenos, su formación no debe olvidar las costumbres o la moral." (De Nebrija, 1981, págs. 120-121).

Mul- /fol. 258v/ tum haec observantia studio confert. "Estas normas ayudan mucho a la formación, ..." (De Nebrija, 1981, págs. 148-149).

\section{Formas, forma, deformación, malformación}

Et quoniam circa corporis dispositionem adhuc versamur, altera subest cura, ut sive ex partus violentia, sive naturali compositione aliquid depravatum distortumque a naturali habitudine puero agnatum est, emendetur id dum tener est, flectique in quascumque formas.

"Puesto que tratamos de la disposición del cuerpo de los niños, hay que decir otra cosa: si por la violencia del parto o por la natural composición del cuerpo se observa alguna deformidad o malformación, debe ponerse remedio mientras el niño es tierno y fácil de doblar en distintas formas." (De Nebrija, 1981, págs. 104-105).

(...) cur parents /fol.252r/ alias negligant habitudes, quae possint defortmitatem aliquad praeseferre?

“¿Porqué los padres descuidan ciertas costumbres que pueden originar deformidad?” (De Nebrija, 1981, págs. 104-105)
Neque illud magis tolerandum, quod brachia ad paucos dies quam sunt nati exerunt, quod ipsum lacertos torosque facit imbecilliores.

"No se debe tolerar: que los brazos, a los pocos días de nacer, se coloquen de forma que se desvíen de su natural posición y se distorsionen." (De Nebrija, 1981, págs. 108-109).

\section{Formando}

Non omittenda esta quoque in hac aetate saltatio, quatenus igenuorum filios decet, non gestus motusque totis corporis, ne manus et brachia sint rustice et indocte posita, ne status indecorus, ne qua in proferandis pedibus /fol. $253 \mathrm{r} /$ inscitia, ne caput oculique ab alia corporis inclinatione dissideant, cum praesertim haec chironimia ab illis temporibus Herocis orta sit, \& a Socrate atque Platone in parte virtutum civilium posita, \& a Chrisippo in praeceptis de liberorum educatines non omissa.

"No se permita incorrección en la manera de caminar; ni la cabeza, ni los ojos disientan del movimiento o inclinación del cuerpo. Esta quironimia surgió desde los tiempos heroicos y ha sido colocada por Sócrates y Platón como formando parte de las virtudes cívicas y no omitida por Crisipo al hablar de la educación de los hijos”. (De Nebrija, 1981, págs. 110-111).

\section{Formada}

Mam (is) quamvis trienium nutricibus dederit tamen ab illis quoque iam formandam quam optimis institutis mentem infantium iudicat.

"Piensa este autor que el niño, entregado a los cuidados de la institutriz hasta los tres años, no deja de tener ya su mente en disposición de ser formada con óptimas orientaciones." (De Nebrija, 1981:, págs. 118-119).

\section{Reformarse}

Qui enim frontones dicti sunt \& capitones\& nasones \& chilones \& mactici a magnitudine frontis capitis nasi labrorum et malarum corrigi non posunt, at possunt simi, possunt valgi, possunt flaci.

“(...) por el tamaño de la frente, de la cabeza, de la nariz, de los labios y de las mejillas que no pueden reformarse; pero pueden reformarse los chatos, los zambos, los flacos”. (De Nebrija, 1981, págs. 106-107). 
En este libro, se manifiestan rasgos de una concepción antropológica, que informa de cómo ha de ser el proceso educativo para el ser humano, refiriéndolo a las ideas de instrucción y perfeccionamiento. Incluso en los primeros capítulos, el autor refiere al sentido que educación comienza a tener, en la buena conformación biológica, aspecto que hace posible valorar el reconocimiento que se formula a los aspectos físicos, que no fueron tratados de manera tan explícita en los siglos anteriores.

Otra referencia importante de la producción pedagógica española renacentista, está contenida en el humanismo pedagógico de Juan Luis Vives. De Vives interesan las reflexiones en torno a la entidad humana en la obra De anima et vita ${ }^{10}$, particularmente por la orientación psicologista que imprime a su pensamiento: el alma como principio activo, es decir, por la potencia de ser; la educación como hacer humano, que estaría en función de la eficiencia del alma; el cuerpo, apto para recibir la vitalidad de la potencia del alma, ideas que llevan implícita la posibilidad de la acción de fuerzas que pueden potenciar esa alma. Se trata de la condición de educabilidad humana y la posibilidad formativa como proceso individual y singular, que ya estaban manifiestas en Erasmo de Rotterdam. En esta obra, Vives analiza las operaciones del alma a partir de la reflexión y de la observación empírica. Él observa y describe el mecanismo de las acciones humanas avanzando por un camino que va, desde su origen en el conocimiento sensitivo, hasta las acciones que se realizan por mediación de la voluntad. Es un tratado de carácter filosófico, pero también antropológico, en el que interesa, el estudio de las operaciones mentales, insertas en una referencia de la acción.

Vives proporciona elementos para una teoría de la educación, en la que cabe la formación humana en ámbitos como la sabiduría, la vida misma y su fin. Por lo tanto, su noción de realidad es tridimensional: teleológica -cifrada en la educación-; personal -surge de la comunicación entre maestros y discípulos o padres e hijos-; y mesológica e instrumental -mediada por las disciplinas escolares y los medios que están presentes en el proceso educativo-.

El concepto de ingenio cobra un interés particular: fuerza de la mente que se revela y manifiesta mediante la actividad de sus instrumentos. $\mathrm{Al}$ respecto en el libro III, capítulo I de De anima et vita se lee en "La inteligencia simple":

“a. En verdad, como Dios ha depositado en la tierra las semillas de todas las plantas que luego la misma tierra desarrolla todavía más, aunque sean cultivadas y resulten más idóneas para el uso gracias al cuidado diligente de los hombres; así en la mente de cada uno, las semillas son el inicio, el origen de las artes, de la prudencia y de todos los inicios; de ahí resulta que nacemos idóneos para todo; y no existe, arte o doctrina alguna de la cual no pueda la mente mostrar algún indicio, tosco e insuficiente sin duda, pero, con todo, válido. Ahora bien, este se perfecciona cuando se le han aplicado la ciencia y el ejercicio, como entre las plantas se desarrollan mejor que otros, aquellos a los que el agricultor ha aplicado un cultivo esmerado. Y me refiero al conocimiento de las cosas inmutables por naturaleza, pues las que han sido concebidas por el ingenio del hombre, no pueden aprenderse sin el maestro y la enseñanza, como una lengua: por ejemplo, el latín, el griego o el español. De ahí se deduce que los animales al secundar su primitiva naturaleza, todavía íntegra e incorrupta, no se equivocan al satisfacer sus necesidades, más el hombre que sigue sus propias interpretaciones, se extravía por aquellos senderos que él mismo se ha abierto, tras haber abandonado el camino real. Además los animales de la misma especie obran del mismo modo: es decir, la misma enseñanza y los mismos preceptos de la naturaleza; el hombre en cambio, ya que juzga de forma diferente, obra de modo diverso y hasta contrario". (Vives, 1992, pág. 134).

En este texto se pone de manifiesto esa innata condición humana diferente a la de los animales, en la que el perfeccionamiento es posible, gracias a la mente ${ }^{11}$ que es susceptible de recibir la acción y porque es acción, y que Vives desarrolla bajo el símil de las semillas en la tierra. Desde luego, se encuentra también en su obra, el planteamiento del método para aprender, el cual no es motivo de interés en este momento, pero que deja evidencia, 
desde su concepción, de la acción educativa desde fuera.

Se puede afirmar entonces, que el Renacimiento en España, fue una época en el campo pedagógico en la que se puso especial atención al proceso moral; que comprendió no sólo, el cómo es el ser humano, es decir, la preocupación ontológica y antropológica por el ser, sino, el cómo ha de ser, que construye una dimensión teleológica. La educación siempre es teleológica, pero ese telos es el que adquirió un sentido distinto en el Renacimiento respecto a otros momentos, y con él, se asistió a un proceso de diferenciación del concepto de formación respecto al de educación con el cual, ha corrido aparejado.

\section{En torno a la posible aparición del concepto de formación en el lenguaje}

Interesa ubicar ahora en la evolución de la idea de formación para constituirse en palabra. Si se parte de que en España el proceso de traspaso de la Edad Media al Renacimiento fue un proceso lento, que no ofreció grandes rupturas y que respecto a otros países de Europa, el Renacimiento fue más bien un período tardío, y si hay consenso en que el término "forma" como semicultismo y por lo tanto como préstamo de una lengua -el latín- a otra -el romance-, entonces cabe entender que el concepto formación entrara o se constituyera concretamente, en palabra castellana con significación pedagógica explícita, más bien tardíamente, cerca del fin del siglo XVI y no antes. Y que encontró en el pensamiento renacentista, territorio adecuado para germinar. No obstante conviene anteponer algunas reflexiones.

El término formación es una palabra derivada del semicultismo 'förma' ${ }^{12}$. En ese sentido, su construcción y uso como concepto de significación pedagógica, hay que ubicarlos necesariamente en aquellos ámbitos en los que el latín constituía una lengua de fuerte arraigo e influencia en el campo cultural y desde ahí educativo, como es el caso de los monasterios, las universidades, los colegios en dos épocas: el proceso arranca en la Baja Edad Media y se consolida en el Renacimiento, a finales del siglo, concretamente en el siglo XVI ${ }^{13}$.

Ampliando la idea, una lengua, que no es sólo el producto de creación de un grupo social, es también consecuencia de la labor de creación de las clases más elevadas y de las circunstancias históricoculturales que condicionan su evolución y la de cada vocablo en particular. Una palabra posee un contenido conceptual o afectivo que habla en cada instante, de las circunstancias en las que el vocablo se ha insertado a través de la historia de la lengua. Por ello, se puede proponer que, el término 'formación', como concepto pedagógico se gestó en realidades socio-culturales de procedencia, llamémosla, "culta", entendida en dos sentidos: en sectores más expuestos a acciones de intervención cultural y en la perspectiva lingüística a la que hacen referencia Américo Castro (1936) y Dámaso Alonso (1950) cuando manifiestan que, casi la mitad del léxico castellano es de procedencia culta, es decir, proveniente del préstamo ${ }^{14}$ que en este caso, ha hecho el latín al romance.

La palabra, es ante todo, una realidad semántica que constituye una unidad significativa en la cadena hablada. Es decir, nuevos conceptos requieren de voces nuevas y en el ámbito cultural y educativo en particular, la influencia del cristianismo con el empleo del latín y la incorporación de voces griegas, generó la aparición de cultismos y semicultismos, así como el ámbito de palabras derivadas de ellas. Incluso muchos neologismos entraron en latín, provenientes del griego primero y luego del hebreo. Es el caso de la palabra 'forma' de la cual deriva 'formación', término empleado por los griegos, como se constata en la consulta a diccionarios. Lo que ocurre es que el proceso llevó largos años de gestación. 
Si se toma en cuenta que los tres ambientes que se han planteado para justificar la procedencia de los cultismos han sido: el latín eclesiástico, el ambiente jurídico y el ambiente escolar y, los campos nocionales en que se inscriben, es decir, los términos eclesiásticos y religiosos; los conceptos teológicos-filosóficos; la moral; las voces jurídicas y, los cultismos escolares y científicos, se puede encontrar entonces, una especie de plataforma para afianzar la idea de que el término formación, tuviera en el Renacimiento en el siglo XVI, las condiciones idóneas para ser construido como concepto educativo y que su significación estuviese, como lo estuvo el concepto mismo de educación, situado en la esfera de lo religioso-filosófico.

\section{Conclusiones}

El Renacimiento estuvo, en el campo pedagógico, fundamentado, manifiesto y apoyado, en una literatura didáctico-moral, y planteó una educación incardinada en el individuo en tanto sujeto perteneciente a una comunidad que está además estructurada en una jerarquía de clases sociales, por lo tanto, se trataba de una educación entronizada como cultura, con un claro reconocimiento a los aportes que podrían derivarse de otras culturas, como la cristiana. Desde esta perspectiva, 'formación' como concepto pedagógico germina en un lento proceso de diferenciación, en la medida en que la educación se afianza en la institucionalización y se construye como recurso político mediante el poder de las clases cultural y políticamente dominantes.

Humanistas renacentistas del calibre de Erasmo de Rotterdam y Juan Luis Vives, proporcionan ideas educativas vinculantes con el concepto 'formación'. Al respecto, Erasmo proporciona la noción de educabilidad y la de vocación. La primera, inscrita en la naturaleza humana, es fundante del concepto 'formación', en la misma idea de García Carrasco y García del Dujo.

Desde los aportes de Elio Antonio Nebrija, las obras De liberis educandis y el Vocabulario Latino-español, constituyen dos valiosos referentes para esta aproximación semántica al concepto pedagógico formación. De liberis educandis o De la educación de los hijos, facilita desde el lenguaje usado, una aproximación al campo de significaciones pedagógicas. En el caso de Luna Luis Vives, concibe la condición de educabilidad humana y la posibilidad formativa como proceso individual y singular, que ya estaban manifiestas en Erasmo de Rotterdam. Vives proporciona elementos para una teoría de la educación, en la que cabe la formación humana en ámbitos como la sabiduría, la vida misma y su fin, por lo que el perfeccionamiento es posible, gracias a la mente ${ }^{15}$.

En el Renacimiento hay importantes referencias al universo semántico del término y se manifiestan rasgos de una concepción antropológica, que informa de cómo ha de ser el proceso educativo para el ser humano, refiriéndolo a las ideas de instrucción y perfeccionamiento.

El Renacimiento en España, en el campo pedagógico fortaleció la perspectiva moral, la cual comprendió la preocupación ontológica y antropológica y la dimensión teleológica del ser humano. Al ser la educación teleológica, ese telos adquirió un sentido particular en el Renacimiento respecto a otros momentos. Con ello se asistió a un proceso de diferenciación del concepto de formación en relación con el de educación con el cual, ha corrido aparejado.

Finalmente, se puede decir, que 'formación', como concepto pedagógico se construyó en realidades socio-culturales de procedencia "culta" en el ámbito cultural y educativo en particular. En ese sentido, la influencia del cristianismo contribuyó a la aparición de cultismos y semicultismos, desde el empleo del latín y la incorporación de voces griegas. Numerosas palabras derivadas de ellas, dieron 
origen a neologismos que ingresaron en latín, por lo que se sostiene la hipótesis de que al igual que el concepto de educación, tuvo su génesis como concepto pedagógico, en el Renacimiento y en la esfera de lo religioso-filosófico.

\section{Notas}

1. Considerado como el padre de la civilización moderna, su humanismo cristiano pone en evidencia los elementos configuradores de su preparación monacal.

2. Es la perspectiva platónica de la educación: la educación es educación política o politeia, la participación del ciudadano en los asuntos de la polis. Si la paideia es politeia, entonces la educación está vinculada a la diké o virtud política más importantes: justicia. Politeia, paideia y diké forman un tríptico fundamental en la visión educativa de Platón.

3. Publicada en 1516. Citado por Capitán, Op. Cit. Refiere a la obra en: Erasmo, D. La educación del príncipe cristiano. En Obras Escogidas. Madrid: Aguilar. 1964, pág. 276.

4. Puede verse la obra de Guarino Guarini de Verona, quien vivió a finales del siglo XIV y primera mitad del XV. Convencido de que la educación era el medio para lograr la intimidad espiritual y extender a todas las clases sociales la cultura y civilización antiguas, del que era excelente estudioso, puso como ejes de la formación humana, el saber y la virtud. Con ello, se instala el conocimiento acompañado de la virtud. Entendido el ser humano como totalidad, reconoció el valor de la memoria, la inteligencia, el conocimiento o saber, la virtud y la religión y concibió a la escuela organizada en tres niveles: elemental o propedéutico, gramatical y superior o histórico o retórico.

5. $\quad \mathrm{Al}$ respecto, véase la obra de Victorino Rambaldoni, en la Casa Giocosa, donde se presenta el ideal de la escuela humanista en una clara simbiosis de la tradición cristiana y la cultura clásica.

6. Ver la obra: Doctrinal de Caballeros. (Burgos, 1487), donde se perfila el ideal del caballero cristiano y en la que se reúne la filosofía cristiana y el estoicismo de Séneca. Según Capitán. (1984). Op. Cit.
7. Manifiestas en Diálogo de Bias contra Fortuna; Doctrinal de privados y Proverbios.

8. Nos interesa principalmente, Universal Vocabulario, que es anterior al de Nebrija.

9. Empleamos acá la edición de De Nebrija (1981) que es un estudio, edición y traducción con notas de León Esteban y Laureano Robles.

10. Tratado del alma (De anima et vita). Escrita en el año 1538, dos años antes de su muerte. Representa una obra de su madurez que es producida en ese contexto que marca la modernidad y el antropocentrismo. Está claramente impregnada de conceptos aristotélicos y del pensamiento de Santo Tomás de Aquino. La obra dividida en tres libros trata de: El alma de los animales; El alma racional; Las emociones. Véase: Vives (1992).

11. En otro capítulo, de la misma obra, Vives nos dice respecto a la mente: “... Nuestra mente es acto, no puede cesar enteramente su actividad, a no ser que se oponga válidamente una fuerza...”. Página 181 de la obra citada.

12. Corominas (1987) documenta: Cejador IX, 166; Glosas de Silos; documentos de 1206; textos medievales; Alonso de Palencia (46d, 143b, 161b, 213d); Elio Antonio Nebrija, 166; Glosas de Silos; documentos de 1206; textos medievales; Alonso de Palencia (46d, 143b, 161b, 213d); Elio Antonio Nebrija.

13. Aquí cabe una breve aclaración: la demarcación lingüística medieval que se emplea en este trabajo es la que propone Martín Alonso Pedraz, en la obra: Alonso (1986). Comienza en el siglo XII con el Poema del Mío Cid y preámbulos difusos y embrionarios en los siglos X y XI y comprende las cabezas puente con dialectos como el mozárabe, leonés, aragonés y castellano y acaba en el siglo XV con los diccionarios de Alonso de Palencia y Elio Antonio Nebrija. Por lo tanto, cuando se habla del renacimiento, se está asumiendo que hasta el siglo XV, se traslapan esos siglos con la Edad Media lingüística.

14. En el caso de los cultismos hablamos de un préstamo que supone la existencia de dos lenguas, que serían para nosotros, el latín y el romance. El latín que fue perdiendo vigencia como lengua hablada, fue ganando como lengua de cultura. Tanto el latín como el romance, se fueron diferenciando, pero en términos de sus 
finalidades y la historia de la lengua castellana, nos remite a que lo que tuvimos fue un trasvase del latín al romance. La lengua de la baja latinidad y en especial el latín medieval, es el que nos sirve de referente cuando analizamos el préstamo culto. En épocas de gran presión cultural aparecen los neologismos y se da una especie de comunicación en doble vía. En este caso, una latinización del romance y una romanización del latín, proceso que venía acuñándose desde el siglo XII. Un buen ejemplo, lo encontramos en Berceo. Véase al respecto: De Bustos (1974).

15. En otro capítulo, de la misma obra, Vives dice respecto a la mente: “... Nuestra mente es acto, no puede cesar enteramente su actividad, a no ser que se oponga válidamente una fuerza...”. Página 181 de la obra citada.

\section{Referencias bibliográficas}

"De liberis educandis" en Revista de Archivos, Biblioteca y Museos, año VII, T. IX, Julio - Diciembre. 1903.

Alonso Pedraz, Martín. Diccionario Medieval Español. Desde las Glosas Emilianenses y Silenses (s. X) hasta el siglo XV. Tomos I y II. Salamanca: Universidad Pontifica de Salamanca. 1986.

Alonso, Dámaso. La lengua poética de Góngora. Anejo de la R.F.E. Madrid. 1950 .

Capitán Díaz, Alfonso. Historia del pensamiento pedagógico en Europa. Desde sus orígenes al precientificismo pedagógico de J.F. Herbart. España: Dykinson. 1984.
Castro, Américo. Glosarios latino-españoles de la Edad Media. Madrid: Centro de Estudios Históricos. 1936.

Corominas, Joan. Breve diccionario etimológico de la lengua castellana. III edición muy revisada y mejorada. Diccionarios 2. Madrid: Editorial Gredos S.A. 1987.

De Bustos Tovar, José Jesús. Contribución al estudio del cultismo léxico medieval. Anejos del Boletín de la Real Academia Española. Anejo XXVIII. Madrid: Imprenta Aguirre. 1974.

De Nebrija, Elio Antonio. La educación de los hijos. Valencia, España: Universidad de Valencia. 1981.

Delgado Criado, Buenaventura (Coordinador). Historia de la educación en España y América. Tomo 2. Madrid: Ediciones SM. 1993.

García Carrasco, Joaquín; García Del Dujo, Ángel. Teoría de la Educación. Salamanca, España: Ediciones Universidad de Salamanca. 1996.

Lerena, Carlos. Reprimir y liberar. Crítica sociológica de la educación y de la cultura contemporáneas. Madrid: Akal editor / Universitaria. 1983.

Vives, Juan Luis. De anima et vita. 'El alma y la vida'. España: Ayuntamiento de Valencia. 1992.

María Eugenia Venegas Renauld Docente de la Universidad de Costa Rica 